\title{
Efficient Exciton Harvesting through Long-Range Energy Transfer
}

$\operatorname{AUTHOR}(S)$ :

Wang, Yanbin; Ohkita, Hideo; Benten, Hiroaki; Ito, Shinzaburo

CITATION:

Wang, Yanbin ...[et al]. Efficient Exciton Harvesting through Long-Range Energy Transfer. ChemPhysChem 2015, 16(6): 1263-1267

ISSUE DATE:

2015-04-27

URL:

http://hdl.handle.net/2433/217955

\section{RIGHT:}

This is the accepted version of the following article: [Wang, Y., Ohkita, H., Benten, H. and Ito, S. (2015), Efficient Exciton Harvesting through Long-Range Energy Transfer. ChemPhysChem, 16: 1263-1267], which has been published in final form at http://doi.org/10.1002/cphc.201402740. This article may be used for non-commercial purposes in accordance with Wiley Terms and Conditions for Self-Archiving.; This is not the published version. Please cite only the published version.; この論文は出版社版でありません。引用の際には出版社版をご確認ご利用ください。 


\title{
Efficient Exciton Harvesting through Long-Range Energy Transfer
}

\author{
Yanbin Wang, ${ }^{[a]}$ Hideo Ohkita, ${ }^{* a, b]}$ Hiroaki Benten, ${ }^{[a]}$ and Shinzaburo Ito ${ }^{[a]}$
}

Efficient exciton collection to charge generation sites is one of the key issues for the improvement in power conversion efficiency (PCE) of organic solar cells because only excitons arriving at a donor/acceptor interface can be dissociated into free charge carriers. We have evaluated the effective diffusion length in poly(3hexylthiophene) (P3HT) by using donor/acceptor bilayers with two different exciton-quenching acceptors. One is an insoluble fullerene polymer ( $\mathrm{p}$-PCBVB), which is an efficient electronaccepting material with negligible absorption in the visible region. The other is a low-bandgap polymer, poly[(4,4-bis(2-ethylhexyl)-

\section{Introduction}

Polymer solar cells have attracted a great deal of attention because of their potential applications to flexible, light-weight, and large-area devices. ${ }^{[1-3]}$ The active layer of them is typically based on bulk heterojunction structures, which consist of donor and acceptor materials with interpenetrating nanoscale networks to maximize the donor/acceptor interfacial area. In polymer solar cells, excitons (coulombically bound electron-hole pairs) should be transferred to the donor/acceptor interface to be efficiently dissociated into free electron and hole carriers because of the strong binding energy. ${ }^{[4-6]}$ However, the exciton diffusion length in most conjugated polymers is as short as $5-20$ $\mathrm{nm},{ }^{[7-15]}$ which is not always enough to make sure all the excitons generated reach the interface of polymer/fullerene before deactivating to the ground state. For example, it has been reported that about $10-20 \%$ excitons are lost before arriving at the interface even in a benchmark solar cell based on poly(3-hexylthiophene) (P3HT) and a fullerene derivative (PCBM). ${ }^{[16,17]}$ Therefore, the efficient exciton harvesting is required for further improvement in polymer solar cells.

Energy transfer is long-range exciton transport and hence could collect exciton energy more efficiently to specific sites than random exciton diffusion if energy donating and accepting materials are allocated appropriately. ${ }^{[17-21]}$ Indeed, we have recently shown that $\mathrm{P} 3 \mathrm{HT}$ excitons are collected more efficiently to a low-bandgap dye molecule silicon phthalocyanine derivative (SiPc) located at a donor/acceptor interface in P3HT/PCBM blends. ${ }^{[17,21-23]}$ As a result of such appropriate incorporation of $\mathrm{SiPc}$, the external quantum efficiency (EQE) is improved not only at the dye absorption band in the near-IR region but also at the $\mathrm{P} 3 \mathrm{HT}$ absorption band in the visible region. The former is ascribed to the additional light-harvesting by SiPc dye molecules. The latter is ascribed to long-range energy transfer from P3HT

[a] Dr. Y. Wang, Dr. H. Ohkita, Dr. H. Benten, Prof. S. Ito, Department of Polymer Chemistry, Graduate School of Engineering, Kyoto University, Katsura, Nishikyo, Kyoto 615-8510, Japan E-mail:ohkita@photo.polym.kyoto-u.ac.jp

[b] Dr. H. Ohkita

Japan Science and Technology Agency (JST), PRESTO, 4-1-8 Honcho Kawaguchi, Saitama 332-0012, Japan dithieno[3,2-b:2',3'-d]silole)-2,6-diyl-alt-(2,1,3-benzothiadiazole)-4,7diyl], (PSBTBT). This polymer has a large absorption band in the near-IR region, which is well overlapped with the emission band of $\mathrm{P} 3 \mathrm{HT}$. The effective diffusion length of $\mathrm{P} 3 \mathrm{HT}$ excitons is evaluated to be $15 \mathrm{~nm}$ for P3HT/p-PCBVB bilayers and improved to $30 \mathrm{~nm}$ for P3HT/PSBTBT bilayers. This improvement is ascribed to longrange energy transfer from $\mathrm{P} 3 \mathrm{HT}$ to PSBTBT. This finding suggests that effective diffusion length of $\mathrm{P} 3 \mathrm{HT}$ excitons can be increased through long-range energy transfer by incorporating PSBTBT to P3HT/PCBM blends.

to $\mathrm{SiPc}$ at the heterojunction of P3HT/PCBM blends. Because of the spectral overlap between P3HT emission and SiPc absorption bands, the Förster radius is as long as $3.7 \mathrm{~nm}$, which is enough long compared to a hopping length of excitons. In $\mathrm{P} 3 \mathrm{HT} / \mathrm{PCBM} / \mathrm{SiPc}$ ternary blends, half of P3HT excitons that would be lost in the absence of SiPc are collected by energy transfer to SiPc molecules at the heterojunction. Consequently, our finding demonstrates that the energy transfer can increase the effective exciton diffusion length.

Recently, the photocurrent improvement has been reported for ternary blend solar cells based on P3HT, PCBM, and a low-
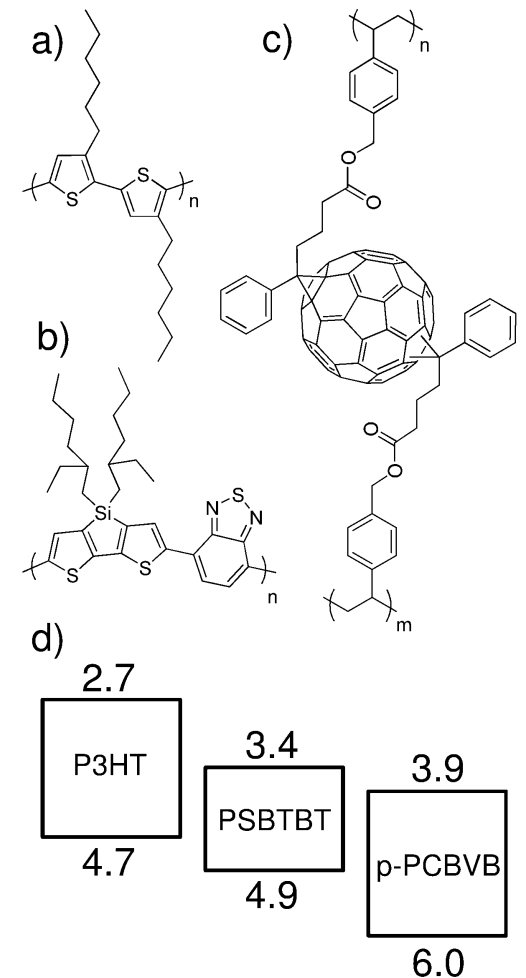

Scheme 1. Chemical structures of materials used in this study: a) P3HT, b) PSBTBT, and c) p-PCBVB. d) The HOMO (lower) and LUMO (upper) energy levels of these materials. 
bandgap polymer PSBTBT. ${ }^{[24-28]}$ This was primarily ascribed to the additional light-harvesting in the near-IR region due to PSBTBT. We speculate that the energy transfer from $\mathrm{P} 3 \mathrm{HT}$ to PSBTBT would improve the exciton harvesting and hence the device performance in this ternary blend solar cells because of the spectral overlap between P3HT emission and PSBTBT absorption bands. Herein, we study the effective diffusion length of P3HT excitons to PSBTBT domains in order to address how energy transfer impacts on the diffusion length in P3HT/PSBTBT/PCBM ternary blends. To evaluate the exciton diffusion length of $\mathrm{P} 3 \mathrm{HT}$ excitons correctly, we employed bilayer films based on P3HT and insoluble fullerene polymer ( $p$-PCBVB) In these polymer/fullerene bilayers, $\mathrm{P} 3 \mathrm{HT}$ excitons would be quenched dominantly by electron transfer at the interface. On the other hand, the effective diffusion length of $\mathrm{P} 3 \mathrm{HT}$ excitons was evaluated for P3HT/PSBTBT bilayers in comparison with that in $\mathrm{P} 3 \mathrm{HT} / \mathrm{p}-\mathrm{PCBVB}$ bilayers. In these polymer/polymer bilayers, P3HT excitons would be quenched dominantly by energy transfer to the interface.

\section{Theory}

The continuity equation of the exciton density in onedimensional diffusion is given by Equation (1)

$\frac{\partial n(x, t)}{\partial t}=D \frac{\partial^{2} n(x, t)}{\partial x^{2}}-\frac{n(x, t)}{\tau}+G(x)$

where $n(x, t)$ is the exciton density at a position $x$ and time $t, D$ is the exciton diffusion coefficient, $\tau$ is the exciton lifetime without quenching wall, and $G(x)$ is the exciton generation rate at a position $x$. Under steady state condition, this equation can be solved with two boundary conditions at the two interfaces [Eqs. (2) and (3)].

$n(L, t)=0$

$\left.D \frac{\partial n(x, t)}{\partial x}\right|_{x=0}=0$

In Equation (2), it is assumed that all the excitons arriving at the interface $x=L$ are quenched with $100 \%$ efficiency. In Equation (3), it is assumed that the excitons arriving at the air/polymer interface $x=0$ are not quenched at all and just reflected. In this manner, an analytical expression for the exciton quenching efficiency $Q(L)$ is given by Equation (4) as a function of the polymer film thickness $L$

$$
=\frac{\left[\alpha^{2} L_{\mathrm{D}}^{2}+\alpha L_{\mathrm{D}} \tanh \left(\frac{L}{L_{\mathrm{D}}}\right)\right] \exp (-\alpha L)-\alpha^{2} L_{\mathrm{D}}^{2}\left[\cosh \left(\frac{L}{L_{D}}\right)\right]^{-1}}{\left(1-\alpha^{2} L_{\mathrm{D}}^{2}\right)[1-\exp (-\alpha L)]}
$$

where $\alpha$ as the absorption coefficient of the donor material and the exciton diffusion length $L_{D}=\sqrt{D \tau}$.

When excitons are quenched not only by electron transfer at the interface but also by long-range energy transfer to the interface $x=L$, an additional quenching term should be added to
Equation (1). This is true for low-bandgap acceptors such as PSBTBT. In this case, an additional quenching term is added as shown in Equation (5). ${ }^{[19]}$

$\frac{\partial n(x, t)}{\partial t}=D \frac{\partial^{2} n(x, t)}{\partial x^{2}}-\frac{n(x, t)}{\tau}-k_{\mathrm{EnT}}(x) n(x, t)+G(x)$

Here, $k_{\operatorname{EnT}}(x)$ is the energy transfer rate from position $x$ to the interface $x=L$, which is given by Equation (6)

$k_{\mathrm{EnT}}(x)=\frac{C_{\mathrm{A}}}{\tau} \frac{\pi}{6} \frac{R_{0}^{6}}{(L-x)^{3}}$

where $C_{\mathrm{A}}$ is the density of energy-accepting molecules, and $R_{0}$ is the Förster radius. McGehee et al. reported that the exciton diffusion length effectively increases in the presence of the energy transfer mechanism. Interestingly, they also found that the exciton quenching data in the presence of the energy transfer can be still well reproduced by Equation (4) even though only exciton diffusion is considered. ${ }^{[20]}$ For comparison, we therefore evaluate the effective diffusion length by Equation (4) for the exciton quenching in the absence and presence of longrange energy transfer.

\section{Results and Discussion}

\subsection{Optoelectronic Properties}

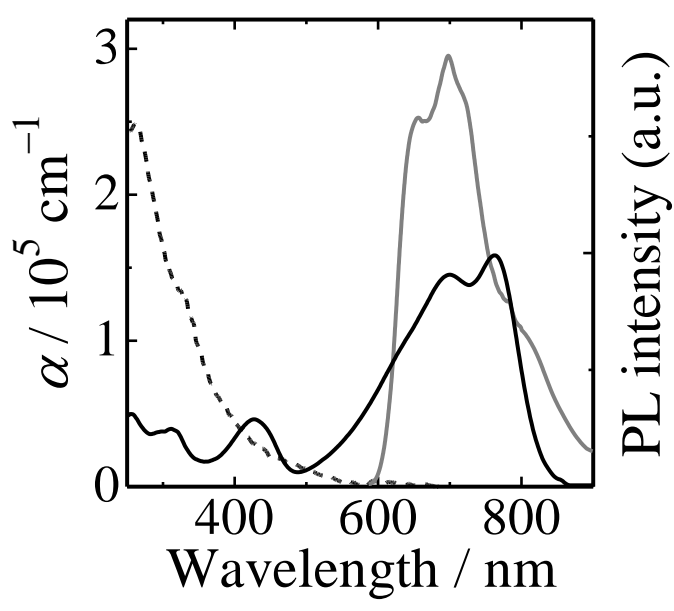

Figure 1. Absorption spectra of PSBTBT (black solid line) and p-PCBVB (black broken line) and PL spectrum of P3HT (gray line) neat films.

The highest occupied molecular orbital (HOMO) level was estimated to be $4.7 \mathrm{eV}$ for P3HT, $4.9 \mathrm{eV}$ for PSBTBT, and 6.0 $\mathrm{eV}$ for $\mathrm{p}$-PCBVB in the solid state by photoemission yield spectroscopy. The lowest unoccupied molecular orbital (LUMO) level was evaluated to be $2.7 \mathrm{eV}$ for P3HT, $3.4 \mathrm{eV}$ for PSBTBT, and $3.9 \mathrm{eV}$ for $\mathrm{p}$-PCBVB from the HOMO level and the optical bandgap estimated from the absorption and emission spectra. As shown in Scheme 1d, these energy structures make sure efficient charge separation between P3HT and P-PCBVB and between P3HT and PSBTBT. As shown in Figure 1, the fullerene polymer $\mathrm{p}$-PCBVB exhibits large absorption in the 
ultraviolet region but negligible absorption in the visible region and the low-bandgap PSBTBT exhibits a large absorption band at around $700 \mathrm{~nm}$ with an absorption coefficient of $145000 \mathrm{~cm}^{-1}$. On the other hand, as shown in the figure, P3HT exhibits an emission band at around $700 \mathrm{~nm}$, which negligibly overlapped with the absorption of $\mathrm{p}$-PCBVB but well overlapped with the absorption band of PSBTBT. From the spectral overlap between the absorption and emission band, the Förster radius is estimated to be as short as $1.6 \mathrm{~nm}$ for the energy transfer from $\mathrm{P} 3 \mathrm{HT}$ to $\mathrm{p}-\mathrm{PCBVB}$ but as long as $3.5 \mathrm{~nm}$ for the energy transfer from P3HT to PSBTBT. These optoelectronic properties indicate that $\mathrm{P} 3 \mathrm{HT}$ excitons are quenched by electron transfer at the interface with p-PCBVB or PSBTBT and also quenched by long-range energy transfer to the interface of PSBTBT.

\subsection{Exciton Diffusion Length}

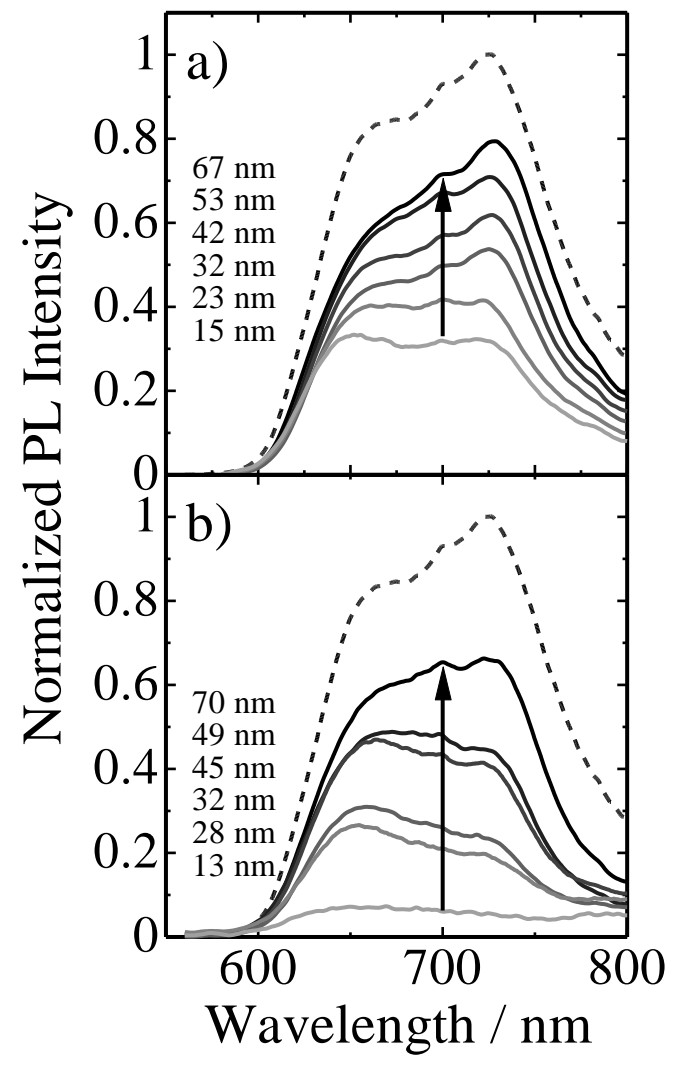

Figure 2. PL spectra of a) P3HT/p-PCBVB and b) P3HT/PSBTBT bilayer films with different P3HT thickness. The broken lines represent the PL spectra of P3HT neat films. The PL intensity of each bilayer film was normalized by the intensity of P3HT neat films with the same thickness.

In order to accurately evaluate the exciton diffusion length, we employ an insoluble fullerene polymer p-PCBVB as an electronaccepting layer in donor/acceptor bilayers instead of small molecule acceptors such as a fullerene derivative PCBM. As reported recently, PCBM molecules are likely to diffuse into the other layer in bilayers even at room temperature. ${ }^{[29]}$ On the other hand, as we reported previously, p-PCBVB insoluble films exhibit flat and smooth surface, which can serve as a suitable quenching wall in donor/acceptor bilayers for evaluating the exciton diffusion length. ${ }^{[9]}$ The thickness of $\mathrm{P} 3 \mathrm{HT}$ layers was varied from 10 to $70 \mathrm{~nm}$, which was precisely evaluated with an absorption coefficient of P3HT. For all the films employed in this study, P3HT was selectively excited in nitrogen atmosphere to prevent $\mathrm{PL}$ quenching at the $\mathrm{P} 3 \mathrm{HT}$ /air surface.

For $\mathrm{P} 3 \mathrm{HT} / \mathrm{p}$-PCBVB bilayers, as shown in Figure $2 \mathrm{a}$, the normalized $\mathrm{PL}$ intensity of $\mathrm{P} 3 \mathrm{HT}$ decreased with decreasing $\mathrm{P} 3 \mathrm{HT}$ thickness. This is because most $\mathrm{P} 3 \mathrm{HT}$ excitons can diffuse to the $\mathrm{P} 3 \mathrm{HT} / \mathrm{p}-\mathrm{PCBVB}$ interface in the thinner $\mathrm{P} 3 \mathrm{HT}$ layer and hence are quenched efficiently. For P3HT/PSBTBT bilayers, as shown in Figure 2b, the normalized PL intensity of P3HT more steeply decreased with decreasing $\mathrm{P} 3 \mathrm{HT}$ thickness than that for P3HT/p-PCBVB. Instead, as shown in Figure 3, the PL band of PSBTBT was observed even though P3HT was selectively excited at $485 \mathrm{~nm}$. The PL intensity due to direct excitation of PSBTBT was negligibly small as shown in the figure: it was as small as $5 \%$ at most because the PSBTBT absorption is the smallest at $485 \mathrm{~nm}$. Thus, the PSBTBT emission observed is indicative of energy transfer from $\mathrm{P} 3 \mathrm{HT}$ to PSBTBT.

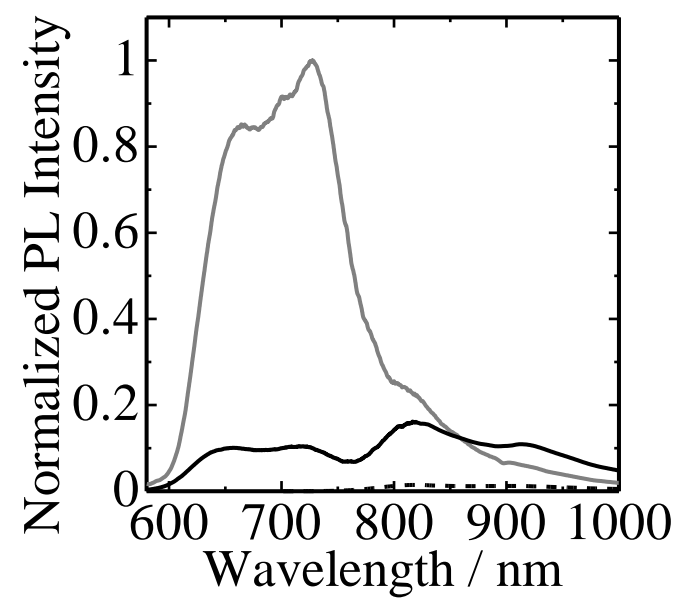

Figure 3. PL spectra of P3HT/PSBTBT bilayer (black line), P3HT neat (gray line), and PSBTBT neat (broken line) films excited at $485 \mathrm{~nm}$. The thickness of each layer was $14 \mathrm{~nm}$ (P3HT) and $20 \mathrm{~nm}$ (PSBTBT).

Figure 4 shows the quenching efficiency of $\mathrm{P} 3 \mathrm{HT}$ in the two bilayer models plotted against the P3HT thickness. The solid lines represent theoretical curves calculated by Equation (4) with various diffusion lengths. For P3HT/p-PCBVB bilayers, as shown in Figure $4 \mathrm{a}$, the quenching efficiency is well fitted with a diffusion length of $15 \mathrm{~nm}$, which is slightly shorter than that in P3HT crystalline domains recently reported $(20 \mathrm{~nm}){ }^{\left[{ }^{[10]}\right.}$ This is probably because the diffusion length evaluated for the bilayer is average of exciton diffusions in amorphous and crystalline domains. For P3HT/PSBTBT bilayers, as shown in Figure $4 \mathrm{~b}$, the quenching efficiency is well fitted with an effective diffusion length of $30 \mathrm{~nm}$, which is two times longer than that for $\mathrm{P} 3 \mathrm{HT} / \mathrm{p}$ PCBVB bilayers. This is because P3HT excitons are more 
effectively collected to the PSBTBT quenching wall by efficient energy transfer.

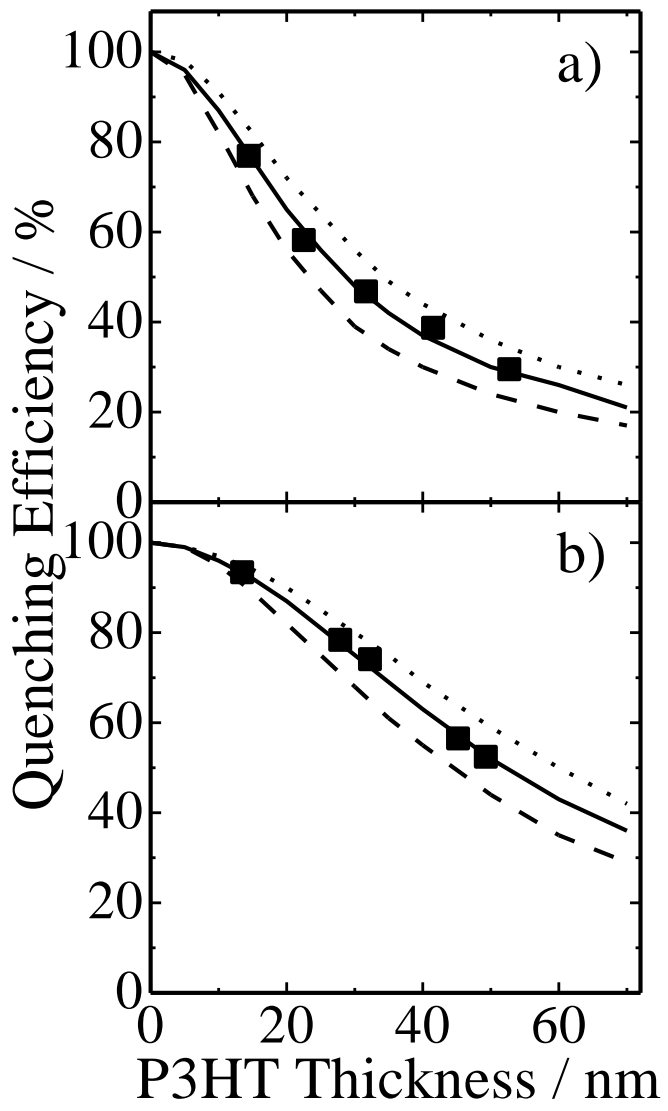

Figure 4. $\mathrm{PL}$ quenching efficiency of a) $\mathrm{P} 3 \mathrm{HT} / \mathrm{p}-\mathrm{PCBVB}$ and $\mathrm{b}$ ) P3HT/PSBTBT bilayer films plotted against P3HT thickness. The broken, solid, and dotted lines represent the PL quenching efficiency calculated by Equation 4 with an exciton diffusion length of 12, 15, and $18 \mathrm{~nm}$ (panel a) and 25, 30, and $35 \mathrm{~nm}$ (panel b), respectively.

Finally, we note the relevance of the effective diffusion length to photovoltaic performance of ternary blend solar cells. More specifically, we focus on ternary solar cells based on $\mathrm{P} 3 \mathrm{HT}$, PSBTBT, and PCBM. In this blend, $\mathrm{P} 3 \mathrm{HT}$ is the most crystalline material and hence would form large crystalline domains under appropriate fabrication conditions such as thermal or solvent annealing. Consequently, PSBTBT also would form phaseseparated domains, which are probably mixed with PCBM as reported previously. ${ }^{[30,31]}$ Typically, phase-separated domain size would be of the order of tens of nanometers, which is consistent with the acceptor thickness employed in this study. We therefore propose that energy transfer from $\mathrm{P} 3 \mathrm{HT}$ to PSBTBT would be efficient in ternary blends with large P3HT crystalline domains. In other words, the energy transfer can harvest more efficiently P3HT excitons that would be lost in such large crystalline domains in the absence of PSBTBT. The large $\mathrm{P} 3 \mathrm{HT}$ crystalline domains would be beneficial for the efficient charge transport and hence improve photovoltaic performance.

\section{Conclusions}

In summary, we demonstrated that the effective diffusion length of singlet excitons can be increased by long-range energy transfer. In P3HT/p-PCBVB bilayer films, the diffusion length of $\mathrm{P} 3 \mathrm{HT}$ excitons is evaluated to be $15 \mathrm{~nm}$, which is slightly shorter than that evaluated for P3HT crystalline domains by singlet exciton-exciton annihilation. In other words, this exciton diffusion length is an average value for $\mathrm{P} 3 \mathrm{HT}$ amorphous and crystalline domains. In P3HT/PSBTBT bilayer films, on the other hand, the effective diffusion length of P3HT excitons is evaluated to be $30 \mathrm{~nm}$. This is most probably because P3HT excitons are more efficiently collected to the PSBTBT quenching wall in the bilayer film. The Förster radius is estimated to be 3.5 $\mathrm{nm}$ for the energy transfer from P3HT to PSBTBT on the basis of the spectral overlap. In ternary blends of P3HT, PSBTBT, and PCBM, the energy transfer would enhance the effective diffusion length as is the case with the bilayer system employed in this study. We therefore propose that growing large P3HT crystalline domains would be the key to the improvement in photovoltaic performance of P3HT/PSBTBT/PCBM ternary solar cells.

\section{Experimental Section}

\section{Materials}

A cross-linkable bi-functionalized fullerene derivative (bis-PCBVB) was synthesized according to literatures. ${ }^{[32,33]}$ The insoluble fullerene polymer p-PCBVB was obtained by thermal cross-linking of bis-PCBVB at $170^{\circ} \mathrm{C}$ for $1 \mathrm{~h}$. The details have been described elsewhere ${ }^{[9]}$ The other chemicals were used without any purification unless otherwise noted: P3HT (Sigma-Aldrich, regioregular, $M_{\mathrm{n}}=87,000 \mathrm{~g} \mathrm{~mol}^{-1}$ ) and PSBTBT (Solarmer Materials Inc., $M_{n}=11,900 \mathrm{~g} \mathrm{~mol}^{-1}$ ). The chemical structures and energy levels of materials used in this study are summarized in Scheme 1 .

\section{Fabrication of Bilayers}

Bilayer films of P3HT/p-PCBVB were fabricated as follows. First, bis PCBVB layer was spin-coated on quartz substrates from chlorobenzene solution ( $4 \mathrm{mg} \mathrm{mL}^{-1}$ ) at a spin rate of $1000 \mathrm{rpm}$ for $60 \mathrm{~s}$. Prior to the spincoating, the quartz substrates were washed by ultrasonication in toluene, acetone, and ethanol for $15 \mathrm{~min}$ in sequence, dried with nitrogen gas, and then cleaned with UV-ozone cleaner for $30 \mathrm{~min}$. Subsequently, the bis-PCBVB film was thermally annealed at $170{ }^{\circ} \mathrm{C}$ for $1 \mathrm{~h}$ under nitrogen atmosphere to be converted to cross-linked and insoluble p-PCBVB film The $\mathrm{p}$-PCBVB film was rinsed with chlorobenzene twice and dried for next step. On the other hand, polymer layers were separately prepared on glass substrates by successive spin-coatings of poly(sodium 4styrenesulfonate) (PSS: Sigma-Aldrich, $M_{\mathrm{w}}=70,000 \mathrm{~g} \mathrm{~mol}^{-1}$ ) and P3HT, resulting in a layered structure with glass/PSS/P3HT. Here, PSS was employed as a sacrificial layer and prepared by spin-coating on precleaned glass substrates from an aqueous solution of PSS $\left(10 \mathrm{mg} \mathrm{mL}^{-1}\right)$ at a spin rate of at $400 \mathrm{rpm}$ for $10 \mathrm{~s}$ and $4000 \mathrm{rpm}$ for $30 \mathrm{~s}$. By immersing the glass substrate coated with PSS/P3HT into water slowly, the P3HT layer was floated on the water because the PSS sacrificial layer was selectively dissolved. Finally, the quartz substrate coated with p-PCBVB was gently placed on the P3HT film to obtain a bilayer film of $\mathrm{P} 3 \mathrm{HT} / \mathrm{p}-\mathrm{PCBVB}$.

Bilayer films of P3HT/PSBTBT were fabricated in a similar fashion. First, PSBTBT layer was prepared by spin-coating on the cleaned quartz 
substrate from a chlorobenzene solution with a concentration of $4 \mathrm{mg}$ $\mathrm{mL}^{-1}$ at a spin rate of $2000 \mathrm{rpm}$ for $60 \mathrm{~s}$. Subsequently, a P3HT layer was transferred from the water surface to the PSBTBT coated substrate as is the case with $\mathrm{P} 3 \mathrm{HT} / \mathrm{p}-\mathrm{PCBVB}$ bilayers

\section{Measurements}

Absorption and photoluminescence (PL) spectra were measured with a spectrophotometer (Hitachi, U-3500) and a spectrofluorometer (Horiba Jobin Yvon, NanoLog) equipped with a calibrated imaging detector (Horiba Jobin Yvon, iHR320), respectively. The optical bandgap of materials used in this study was evaluated from the wavelength of intersection between the absorption and PL spectra. The film thickness was evaluated with an atomic force microscope (Shimadzu, SPM-9500J) in the contact mode at room temperature. The ionization potential of P3HT, PSBTBT, and p-PCBVB was measured with a photoelectron yield spectrometer (Riken Keiki, AC-3). All the neat films (ca. $60 \mathrm{~nm}$ ) were fabricated by spin-coating from each chlorobenzene solution on the ITO substrate. The threshold energy for the photoelectron emission was estimated on the basis of the cubic root of the photoelectron yield plotted against the incident photon energy.

\section{Acknowledgements}

This work was partly supported by the FIRST program (Development of Organic Photovoltaics toward a Low-Carbon Society: Pioneering Next Generation Solar Cell Technologies and Industries via Multi-manufacturer Cooperation) and the JST PRESTO program (Photoenergy Conversion Systems and Materials for the Next Generation Solar Cells). Y. Wang was sponsored by the China Scholarship Council (CSC).

Keywords: exciton diffusion length • energy transfer • conjugated polymer • low-bandgap polymer • fullerene derivative

[1] M. C. Scharber, N. S. Sariciftci, Prog. Polym. Sci. 2013, 38, 1929-1940.

[2] N. Yeh, P. Yeh, Renew. Sust. Energy Rev. 2013, 21, 421-431.

[3] L. Dou, J. You, Z. Hong, Z. Xu, G. Li, R. A. Street, Y. Yang, Adv. Mater 2013, 25, 6642-6671.

[4] C. Deibel, V. Dyakonov, Rep. Prog. Phys. 2010, 73, 096401.

[5] H. Ohkita, S. Ito, Polymer 2011, 52, 4397-4417.

[6] P. Peumans, A. Yakimov, S. R. Forrest, J. Appl. Phys. 2003, 93, 36933723.

[7] S. M. Menke, R. J. Holmes, Energy Environ. Sci. 2014, 7, 499-512.

[8] C. Leow, T. Ohnishi, M. Matsumura, J. Phys. Chem. C 2014, 118, 71-76.

[9] Y. Wang, H. Benten, S. Ohara, D. Kawamura, H. Ohkita, S. Ito, ACS Appl. Mater. Interfaces 2014, 6, 14108-14115.

[10] Y. Tamai, Y. Matsuura, H. Ohkita, H. Benten, S. Ito, J. Phys. Chem. Lett. 2014, 5, 399-403.

[11] O. V. Mikhnenko, H. Azimi, M. Scharber, M. Morana, P. W. M. Blom, M. A. Loi, Energy Environ. Sci. 2012, 5, 6960-6965.

[12] K. Masuda, Y. Ikeda, M. Ogawa, H. Benten, H. Ohkita, S. Ito, ACS Appl. Mater. Interfaces 2010, 2, 236-245.

[13] A. J. Lewis, A. Ruseckas, O. P. M. Gaudin, G. R. Webster, P. L. Burn, I. D. W. Samuel, Org. Electron. 2006, 7, 452-456.

[14] P. E. Shaw, A. Ruseckas, I. D. W. Samuel, Adv. Mater. 2008, 20, 35163520.

[15] D. E. Markov, E. Amsterdam, P. W. M. Blom, A. B. Sieval, J. C. Hummelen, J. Phys. Chem. A 2005, 109, 5266-5274.

[16] A. L. Ayzner, D. D. Wanger, C. J. Tassone, S. H. Tolbert, B. J. Schwartz, J. Phys. Chem. C 2008, 112, 18711-18716.
[17] S. Honda, T. Nogami, H. Ohkita, H. Benten, S. Ito, ACS Appl. Mater. Interfaces 2009, 4, 804-810.

[18] Y. Liu, M. A. Summers, C. Edder, J. M. J. Frechet, M. D. McGehee, Adv. Mater. 2005, 17, 2960-2964.

[19] S. R. Scully, M. D. McGehee, J. Appl. Phys. 2006, 100, 034907.

[20] S. R. Scully, P. B. Armstrong, C. Edder, J. M. J. Frechet, M. D. McGehee, Adv. Mater. 2007, 19, 2961-2966.

[21] S. Honda, S. Yokoya, H. Ohkita, H. Benten, S. Ito, J. Phys. Chem. C 2011, $115,11306-11317$.

[22] S. Honda, H. Ohkita, H. Benten, S. Ito, Chem. Commun. 2010, 46, 65966598.

[23] S. Honda, H. Ohkita, H. Benten, S. Ito, Adv. Energy Mater. 2011, 1, 588598.

[24] T. Ameri, J. Min, N. Li, F. Machui, D. Baran, M. Forster, K. J. Schottler, D. Dolfen, U. Scherf, C. J. Brabec, Adv. Energy Mater. 2012, 2, 1198-1202.

[25] T. Ameri, T. Heumuller, J. Min, N. Li, G. Matt, U. Scherf, C. J. Brabec, Energy Environ. Sci. 2013, 6, 1796-1801.

[26] M. Koppe, H. J. Egelhaaf, E. Clodic, M. Morana, L. Luer, A. Troeger, V. Sgobba, D. M. Guldi, T. Ameri, C. J. Brabec, Adv. Energy Mater. 2013, 3, 949-958.

[27] N. Li, F. Machui, D. Waller, M. Koppe, C. J. Brabec, Sol. Energy Mater Sol. Cells 2011, 95, 3465-3471.

[28] F. Machui, S. Rathgeber, N. Li, T. America, C. J. Brabec, J. Mater. Chem. 2012, 22, 15570-15577.

[29] N. D. Treat, T. E. Mates, C. J. Hawker, E. J. Kramer, M. L. Chabinyc, Macromolecules 2013, 46, 1002-1007.

[30] M. T. Dang, L. Hirsch, G. Wantz, J. D. Wuest, Chem. Rev. 2013, 113, 3734-3765.

[31] H. Y. Chen, J. Hou, A. E. Hayden, H. Yang, K. N. Houk, Y. Yang, Adv. Mater. 2010, 22, 371-375.

[32] B. Kim, H. R. Yeom, W. Y. Choi, J. Y. Kim, C. Yang, Tetrahedron 2012 68, 6696-6700.

[33] C. H. Hsieh, Y. J. Cheng, P. J. Li, C. H. Chen, M. Dubosc, R. M. Liang, C. S. Hsu, J. Am. Chem. Soc. 2010, 132, 4887-4893. 
Entry for the Table of Contents (Please choose one layout)

\section{ARTICLE}

\section{Efficient exciton harvesting:}

Effective diffusion length of P3HT excitons can be doubled from $15 \mathrm{~nm}$ to $30 \mathrm{~nm}$ in bilayers of a widebandgap polymer P3HT and a lowbandgap polymer PSBTBT. This is mainly due to long-range energy transfer from $\mathrm{P} 3 \mathrm{HT}$ excitons to PSBTBT because of large spectral overlap between P3HT emission and PSBTBT absorption band.
Exciton Diffusion + Energy Transfer

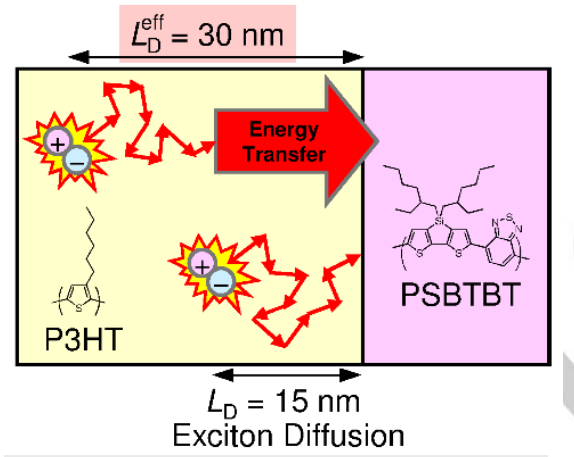

Y. Wang, H. Ohkita, ${ }^{\star} H$. Benten, S. Ito

Page No. - Page No.

Efficient Exciton Harvesting through Long-Range Energy Transfer 